\title{
A inserção do familiar/cuidador no projeto terapêutico singular de pacientes em sofrimento mental: Revisão integrativa
}

The insertion of the family member/caregiver in the singular therapeutic project of patients in mental distress: Integrative review

La inserción del familiar/cuidador en el singular proyecto terapéutico de pacientes en dificultad mental: Revisión integradora

\section{Resumo}

A inserção do familiar/cuidador no projeto terapêutico singular de pacientes em sofrimento mental nos expõe a repensar sobre um novo modelo assistencial de produção do cuidado em saúde mental, onde a inclusão dessa família no projeto não é vista como a causadora da doença mental do indivíduo, e sim é relevante para o desenvolvimento no tratamento do paciente, fortalecendo sua autonomia e reinserção social na comunidade. Portanto, o objetivo desta pesquisa foi mapear os artigos das Bases de Dados, BVS e SciELO, existentes na Literatura Brasileira sobre a inserção do familiar/cuidador no projeto terapêutico de pacientes em sofrimento psíquico nos últimos dez anos. O presente estudo trata-se de uma revisão integrativa, seguindo os passos de Galvão et al. (2008), com a seguinte questão norteadora: "Como se dá, na literatura brasileira, a inserção do familiar/cuidador no projeto terapêutico de pacientes em sofrimento psíquico?". A base de dados selecionada para o estudo foi SciELO (Scientific Library Online) e, também, a busca na Biblioteca Virtual em Saúde (BVS), em que foram selecionados 17 artigos. A partir das nuvens de palavras, foram analisadas as suas dimensões de acesso, em que a família é essencial nesse processo terapêutico assumindo a responsabilidade do cuidado junto ao usuário e à equipe da saúde para promover a autonomia do usuário, retomando a sua cidadania e a reinserção social por meio do cuidado de todos.

Palavras-chave: Família; Projeto terapêutico singular; Saúde mental; Cuidador; Cuidado.

\begin{abstract}
The insertion of the family member/caregiver in the singular therapeutic project of patients in mental distress exposes us to rethink about a new care model for the production of mental health care, where the inclusion of this family in the project is not seen as the cause of the individual's mental illness, but is relevant for the development of the patient's treatment, strengthening their autonomy and social reintegration into the community. Therefore, the objective of this research was to map the articles of the databases, VHL and SciELO, existing in the Brazilian Literature on the insertion of the family member/caregiver in the therapeutic project of patients in psychological distress in the last ten years. The present study is an integrative review, following in the footsteps of Galvão et al. (2008), with the following guide question: "How does the insertion of the family member/caregiver in the therapeutic project of patients in psychological distress take place in the Brazilian literature?". The database selected for the study was SciELO (Scientific Library Online) and also the search in the Virtual Health Library (VHL), in which 17 articles were selected. From the clouds of words, their dimensions of access were analyzed, in which the family is essential in this therapeutic process assuming the responsibility of care with the user and the health team to promote the autonomy of the user, resuming their citizenship and social reintegration through the care of all.
\end{abstract}

Keywords: Family; Singular therapeutic project; Mental health; Carer; Care. 


\begin{abstract}
Resumen
Objetivo: La inserción del familiar/cuidador en el singular proyecto terapéutico de pacientes en angustia mental nos expone a repensar sobre un nuevo modelo de atención para la producción de atención de salud mental, donde la inclusión de esta familia en el proyecto no se ve como la causa de la enfermedad mental del individuo, sino que es relevante para el desarrollo del tratamiento del paciente, fortaleciendo su autonomía y reinserción social en la comunidad. Por lo tanto, el objetivo de esta investigación fue mapear los artículos de las bases de datos, BVS y SciELO, existentes en la Literatura Brasileña sobre la inserción del familiar/cuidador en el proyecto terapéutico de pacientes en angustia psicológica en los últimos diez años. El presente estudio es una revisión integradora, siguiendo los pasos de Galvão et al. (2008), con la siguiente pregunta guía: "¿Cómo se produce en la literatura brasileña la inserción del familiar/cuidador en el proyecto terapéutico de pacientes en dificultad psicológica?". La base de datos seleccionada para el estudio fue SciELO (Scientific Library Online) y también la búsqueda en la Biblioteca Virtual en Salud (BVS), en la que se seleccionaron 17 artículos. Desde las nubes de palabras se analizaron sus dimensiones de acceso, en las que la familia es esencial en este proceso terapéutico asumiendo la responsabilidad del cuidado con el usuario y el equipo sanitario para promover la autonomía del usuario, retomando su ciudadanía y reinserción social a través del cuidado de todos.
\end{abstract}

Palabras clave: Familia; Proyecto terapéutico singular; Salud mental; Cuidador; Cuidado.

\title{
1. Introdução
}

A partir do século XIX, tradicionalmente o único recurso para tratamento de insanidade era o hospital psiquiátrico, onde a forma de tratamento do cuidado ao "doente mental” encontrava-se exatamente ligado à exclusão. Era essencial separar o indivíduo com transtorno mental da sua família e do contato social para realizar o tratamento.

Com o início da Segunda Guerra Mundial, começaram as denúncias sobre os modelos de tratar o louco e a forma de exclusão onde levaram a debates e ocorreram os movimentos para transformação dessas instituições. (Constantinids et al., 2017).

Durante tanto tempo a assistência em saúde mental no Brasil relacionou-se a família como excluída na participação do tratamento dos doentes mentais. Sendo esses doentes reclusos em hospícios. (Moreno \& Alencastre, 2003). Apenas em 1980, com a Reforma Psiquiátrica, determinou-se uma mudança nos modelos assistenciais onde a família era inserida no contexto de apoio aos portadores de transtornos mentais (Moreno \& Alencastre, 2003).

Com a criação da Política Nacional de Saúde Mental brasileira que regulamenta a reforma psiquiátrica no Brasil e redireciona novas formas de assistência, o estado teve que sugerir novas ações políticas assistenciais que contém a participação da Família (Ministério da Saúde, 2001, Conrado et al., 2014).

Como um ponto relevante dessa Lei foi a criação de trabalhos modificativos ao modelo manicomial - Centros de Atenção Psicossocial (CAPS), residências terapêuticas e hospitais-dia- caracterizando-se pela aplicação de um conjunto de tecnologias terapêuticas e psicossociais com o intuito para manter o doente mental junto de sua família e comunidade (Constantinidis et al., 2017).

O modelo essencial dentro desse contexto substitutivo são os Centros de Atenção Psicossocial (CAPS) que se constituem em um trabalho comunitário do Sistema Único de Saúde (SUS), servindo de referência para tratamento de pessoas com transtorno mental. Seu objetivo é a criação de uma autonomia e reinserção social dos pacientes através do trabalho, de seus direitos e deveres enquanto cidadão, lazer e consolidando dos vínculos familiares e comunitários (Carvalho et al., 2012)

Em equipe os CAPS usam como ferramenta de trabalho o Projeto Terapêutico Singular (PTS), contando com a participação do usuário e, em consequência, a criação de sua autonomia. Essa ferramenta reflete as necessidades individuais e a história do indivíduo inserido nesse contexto. Portanto, a. Produção desse projeto ocorre através da atuação singular do profissional de referência e do usuário / família, com toda a equipe, por meio de conflitos e estudo do caso, sendo fundamental a participação do usuário e família nesse processo (Carvalho et al., 2012). 
A mudança do modelo antimanicomial colaborou para um tratamento humanizado favorecendo a reabilitação psicossocial, porém mostrou alguns desafios relevantes referente ao papel dos familiares na preservação do projeto psicossocial.

A família nesse novo modelo de atenção, em algum momento pode se ver desprotegida perante a sua ansiedade por não saber lidar no dia a dia com a rotina do doente, como na condução da medicação, de comportamentos considerados difíceis e as próprias dificuldades do adoecimento (Reis et al., 2016).

Diante disso, perceberam com os estudos que quando um familiar cuidador mora com o paciente, existe uma sobrecarga maior em virtude no aumento das atividades diárias e na ajuda a ser realizada (Almeida, 2010). A expressão 'sobrecarga familiar' ('family burden') está vinculado ao resultado que a presença do paciente com sofrimento psíquico poderá trazer ao ambiente familiar, em todos os aspectos, especialmente aos familiares que cuidam do usuário (Souza Filho, 2010). Provavelmente, os serviços de saúde mental ainda são, não muito presentes na assistência do cuidado proposto pela política de saúde mental, contribuindo para a sobrecarga nas famílias (Reis et al., 2016).

A sobrecarga do familiar ou cuidador pode acarretar grandes consequências ao doente e até a eles mesmo (Cardoso et al., 2012). Mais o conceito da palavra sobrecarga vem sendo estudado em dois aspectos: a sobrecarga objetiva e a sobrecarga subjetiva. A objetiva condiz com alterações que podem ocorrer no dia a dia da família, como limitações da vida profissional e social, gastos financeiros, que podem fazer com que desistam de alguns projetos de vida (Reis et al., 2016).

Já a subjetiva diz respeito as questões emocionais especificas no cuidado com o paciente, como preocupações, informações, sentimentos negativos e outros inúmeros problemas que essa tarefa pode causar (Barroso, Bandeira \& Nascimento, 2007, Reis et al., 2016).

Portanto, o cuidador é um ser humano que pode ser ou não membro da família, disposto a cuidar do paciente dependente ou doente ajudando nas atividades rotineiras da vida, tais como: alimentação, higiene pessoal, na jornada a consultas, bancos ou farmácias isso dissociado da seriedade da doença e do cuidado (Cardoso et al., 2012).

Este tem um papel fundamental no processo de cuidado, por ser um processo dinâmico e que não pode ser auto realizado, em uma situação de crise é necessário o cuidado a saúde para que se determine a condição de saúde e equilíbrio dessa pessoa (Cardoso et al., 2012).

Percebe-se que a alteração na maneira de produzir cuidado vem se afirmando como um processo social difícil, proposto pelo modelo de desinstitucionalização (Severo et al., 2007), ou seja, um cuidado que direciona-se à corresponsabilização e autonomia do indivíduo no seu tratamento, dando-lhe entendimento em seu processo de reabilitação psicossocial, projetos e caminhos terapêuticos ligados ao território e ao fortalecimento do convívio familiar e com sua comunidade (Ayres, 2005, Firmo et al., 2015).

Durante muito tempo a família fora percebida como a causa da doença mental do sujeito, na situação inversa, pensava-se na família como instituição que deveria ser protegida da loucura e do adoecimento de seu familiar, pois este era compreendido como responsável pela desordem social. Uma questão principal no processo de desinstitucionalização era entender o lugar da família nos ajustes de cuidado (Firmo et al., 2015).

Ela deve ser conhecida enquanto agente sociável, apta para definir projetos de sua própria transformação social (Saraceno, 1999). Esta mudança reflete não só na responsabilização da família, mas no potencial existente nela enquanto parceira essencial no papel afetuoso, relacional e cuidador (Carvalho, 2004). Todavia, sua inclusão neste processo tem uma longa trajetória a percorrer, a ser fortalecida numa mudança ideológica centrada na família, perante a sua capacidade de mudança ou de construção do seu papel enquanto cuidadora e protetora (Deslandes \& Barcinski, 2010, p. 307-308, Firmo et al., 2015). 
Diante disso, passa a ser de grande relevância as atividades terapêuticas com a família, em virtude que conviver com a doença implicará em mudanças na dinâmica familiar, nas instabilidades e no estresse durante as crises em que o portador é submetido (Wai-dman, 2004, Conrado et.al., 2014).

Portanto, ao incluir a família no tratamento, torna-se essencial dar um suporte no enfrentamento as dificuldades, pois os incômodos são das duas partes - usuário e família - é atenuado e haverá um aumento de empatia entre eles (Conrado et al., 2014).

Novos serviços de saúde mental apareceram após o movimento antimanicomial e com eles um novo modelo de atenção psicossocial, tendo como peculiaridades o reconhecimento em conhecer as opiniões dos usuários/famílias na criação do projeto terapêutico. Então, a terapêutica não se limitara, em consequência, apenas a remédios e a cirurgia, e sim, considerará a influência terapêutica da escuta e da palavra, no processo da educação em saúde e no apoio psicossocial. (Pinto et al., 2021).

Dessa maneira, o projeto terapêutico engloba a colaboração de diversas especialidades e de diferentes profissões através de discussões de caso e de um grupo multidisciplinar (Jorge et al., 2021). Assim sendo, para a elaboração de um PTS é preciso levar em conta as necessidades de saúde de cada pessoa, seu jeito de entender a vida, suas tendências e particularidades. Através da interação dos responsáveis incluídos no processo de cuidado (trabalhadores e usuários), devem ser baseados nas tecnologias relacionais, promovendo novas formas de cuidado em saúde mental nos diversos níveis de atenção. De acordo com esses achados, perduram, ainda, problemas em desenvolver o PTS como apoio no cuidado interdisciplinar, valorizando a subjetividade e sendo um estímulo a atuação do usuário. Nada obstante, acredita-se que com a conservação do modelo de atenção psicossocial podem ser disponibilizados através da prática do apoio matricial e criação do PTS (Jorge et al., 2021).

Portanto, são nos Centros de Atenção Psicossocial (CAPS) que descreve o PTS como uma prática de ferramenta de trabalho e de cuidados mais especializados e intensos dentro da rede. Os estudos mostram também o PTS como um potente instrumento de cuidado aos indivíduos atendidos nos serviços, permitindo a liberação de sua autonomia e das relações do usuário e suas famílias (Hori et al., 2014).

Além disso, a parte principal para a elaboração do projeto terapêutico é o trabalho em equipe, resultando na participação de reflexões entre vários profissionais nas mais diversas áreas do conhecimento na busca para entender o problema em questão. A construção de um PTS demanda a participação e colaboração de indivíduos engajados com projetos terapêuticos estruturado, incluindo quatro pilares: possível diagnóstico, metas definidas, divisão de responsabilidades e reavaliação (Hori et al., 2014).

Por tanto, esse estudo partiu de uma pergunta propulsora motivando o começo desta busca científica. Como se dá na literatura brasileira a inserção do familiar cuidador no projeto terapêutico de pacientes em sofrimento psíquico?

Diante do exposto, têm-se como objetivo analisar a inserção do familiar /cuidador no projeto terapêutico singular de pacientes em sofrimento mental, e o que vem a ser a participação da família na elaboração desse projeto junto ao paciente e a equipe de profissionais responsáveis, discutindo acerca das possíveis necessidades e estratégias em torno do cuidado para esses sujeitos.

\section{Metodologia}

O estudo faz parte da pesquisa de especialização intitulada: A inserção do familiar/ cuidador no projeto terapêutico singular de pacientes em sofrimento mental. Trata-se de uma Revisão Integrativa (RI), que tem como base os seis estágios estabelecidos por Mendes, Silveira e Galvão (2008), 1) definição do tema e elaboração da pergunta de pesquisa, 2) critérios de elegibilidade, inclusão e exclusão dos estudos, 3) levantamento dos estudos selecionados em formato de tabelas, considerando todas as características em comum, 4) categorização e análise crítica dos achados, identificando diferenças e conflitos, 5) 
interpretação dos resultados e 6) apresentação dos resultados, incluindo análise crítica dos achados e síntese da revisão (Souza et al., 2010).

Para a formulação da questão norteadora do estudo utilizamos a pergunta PCC, a estratégia PICO adaptada. Na adaptação, tal acrônimo significa P- população, C- conceito e C- contexto/desfecho. Assim, a estratégia foi formulada da seguinte maneira: Profissionais e usuários, C- cuidado ampliado em saúde mental, C- ESF e CAPS.

Desta forma, estabeleceu-se, as seguintes questões: como ocorre a inserção do familiar/cuidador no projeto terapêutico singular de usuários da atenção psicossocial em articulação com a atenção primária? O que vem a ser a participação da família na elaboração desse projeto junto ao paciente e a equipe de profissionais responsáveis, discutindo acerca das possíveis necessidades e estratégias em torno do cuidado desses sujeitos.

Após identificação dos Descritores em Ciências da Saúde (DeCS), uma estratégia de busca detalhada, e individual, foi aplicada em cada base de dados: Scielo (Scientific Library Online) e foi realizada busca na Biblioteca Virtual em Saúde (BVS), desenvolvida sob coordenação do Centro Latino-americano de Informação em Ciências da Saúde (BIREME). Sendo incluído todos os artigos publicados até Março de 2021, nos últimos dez anos.

Utilizou-se os seguintes descritores extraídos do DeCS (Descritores em Ciências da Saúde) "saúde mental, "atenção primária à saúde ", "estratégia saúde da família" ", “cuidado", "Família” e uma palavra-chave " Projeto terapêutico singular " não restringindo idiomas, utilizando o operador booleano AND. Durante a estratégia de busca, foram elencados como critérios de inclusão: artigos completos disponíveis integralmente nas bases de dados elencadas nos idiomas português, espanhol e selecionados, artigos referentes aos últimos dez anos, somente artigos científicos e artigos com texto disponível completo. Foram excluídas publicações que preenchia pelo menos um dos seguintes critérios: (1) revisões, (2) artigos duplicados, (3) opinião pessoal de autores, (4) artigos que não se referiam a temática PTS, (5) vídeos.

Figura 1 - Processo de seleção dos estudos.

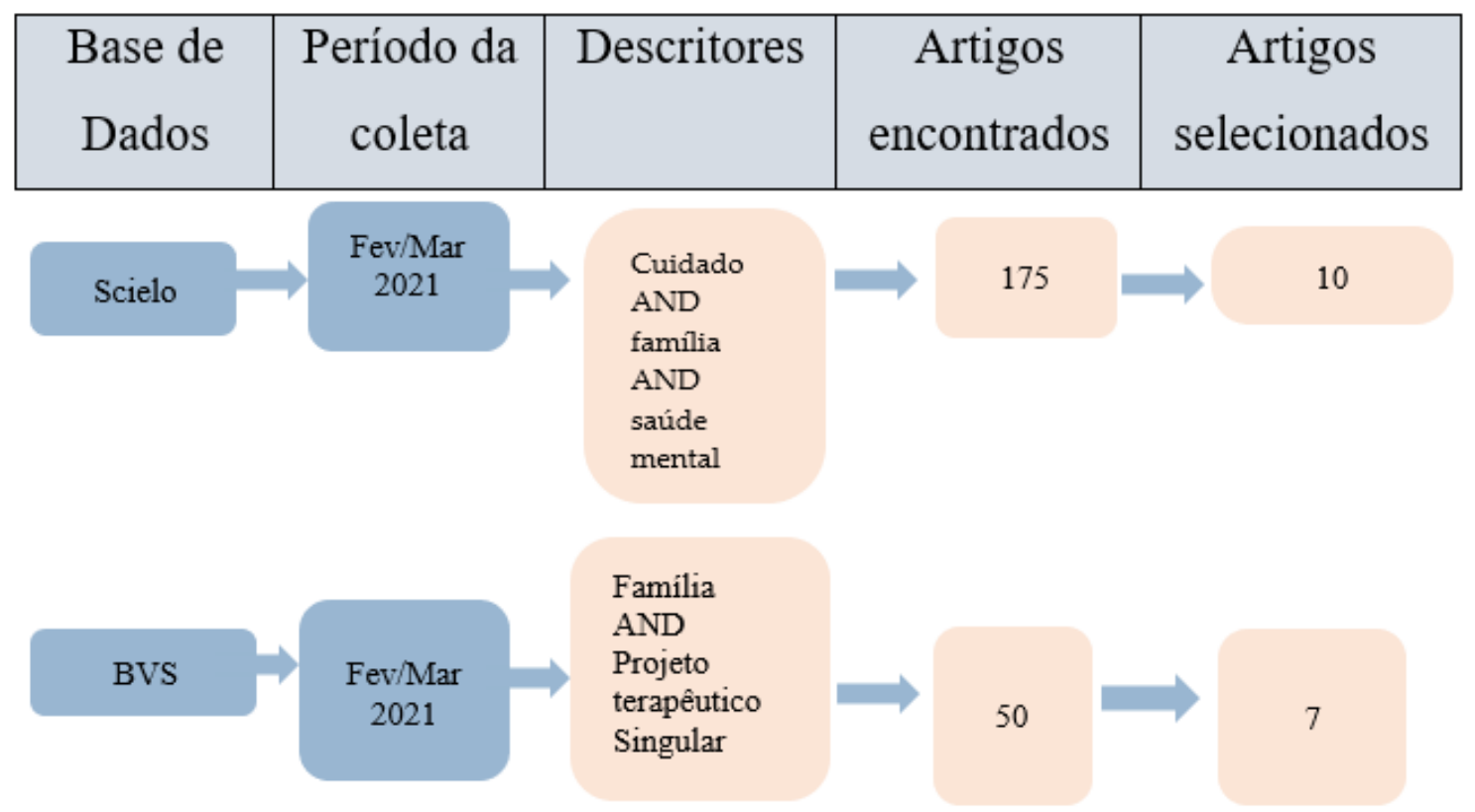

Fonte: Autores.

Referente a este processo de análise das entrevistas, aplicamos a Análise de Conteúdo Categorial Temática proposta por Bardin (2011), definida como um conjunto de técnicas de análise das comunicações que utiliza procedimentos sistemáticos 
e objetivos de descrição do conteúdo das mensagens em três fases: Pré-análise, Exploração do material, Tratamento dos Resultados, Inferência e Interpretação. Na busca por tratar mais sistematicamente o material qualitativo, escolhemos utilizar o software QRS (Qualitative Solutions Research) descrito como NVivo. Entre as principais estruturas deste software estão os NÓS, que podem ser caracterizados como uma estrutura para armazenamento de informações codificadas e podem assumir significados diferentes, dependendo da abordagem metodológica utilizada na pesquisa.

\section{Resultados e Discussão}

Foram selecionados 225 artigos, após a verificação do refinamento caracterizados dentro dos critérios de inclusão e exclusão. Dessa maneira, o tipo de metodologia recomendada nos forneceu dados da literatura teórica e empírica, além de adicionar uma grande variedade de propósitos como, descrição de conceitos, revisão de teorias e indicadores. Ou seja, permitindo uma ampla visão a respeito do tema localizado no campo do indivíduo, no sofrimento mental, no inconsciente e na parcialidade.

Para o cumprimento da seleção desta revisão integrativa selecionamos 17 artigos. Desde o término do processo de reconhecimento e seleção dos estudos foi realizada uma tabela com os estudos pré-selecionados para a Revisão Integrativa baseada no modelo da matriz de síntese como segue abaixo. 
Quadro 1 - Matriz de Síntese dos estudos.

\begin{tabular}{|c|c|c|c|c|c|c|c|c|c|}
\hline $\begin{array}{l}\text { № do } \\
\text { Artigo }\end{array}$ & Título & Autor & Ano & $\begin{array}{c}\text { Título } \\
\text { periódico }\end{array}$ & $\begin{array}{l}\text { Tirado } \\
\text { do } \\
\text { site }\end{array}$ & $\begin{array}{l}\text { Data de } \\
\text { acesso }\end{array}$ & Método & Síntese & Palavra-chave \\
\hline 01 & $\begin{array}{l}\text { O projeto terapêutico } \\
\text { singular como estratégia de } \\
\text { organização do cuidado nos } \\
\text { serviços de saúde mental. }\end{array}$ & $\begin{array}{l}\text { BOCCARDO, A.C.S: } \\
\text { ZANE,F.C; } \\
\text { RODRIGUES,S; } \\
\text { MÂNGLIA, E.F. }\end{array}$ & 2011 & $\begin{array}{l}\text { Revista Terapia } \\
\text { ocupacional da } \\
\text { universidade de } \\
\text { São Paulo, USP. }\end{array}$ & BVS & $01-04 / 2011$ & $\begin{array}{l}\text { Este é um estudo teórico que buscou } \\
\text { sustentação na literatura nacional. A busca foi } \\
\text { desenvolvida a partir de consultas as bases: } \\
\text { SciELO, DEDALUS USP, Google acadêmico e site } \\
\text { do Ministério da Saúde. Para a busca foram } \\
\text { utilizadas as seguintes palavras chave: projeto } \\
\text { terapêutico, saúde mental, CAPS, trabalho em } \\
\text { equipe e organização do trabalho. }\end{array}$ & $\begin{array}{l}\text { Este trabalho teve como objetivo } \\
\text { compreender e discutir a } \\
\text { importância da construção de } \\
\text { projetos terapêuticos como } \\
\text { estratégia de organização do } \\
\text { cuidado nos serviços de saúde } \\
\text { mental e identificar os princípios e } \\
\text { diretrizes essenciais para a sua } \\
\text { operacionalização. }\end{array}$ & $\begin{array}{l}\text { Serviços de saúde mental; } \\
\text { Atenção à saúde; Serviços } \\
\text { comunitários de saúde } \\
\text { mental; Desenvolvimento } \\
\text { tecnológico. }\end{array}$ \\
\hline 02 & $\begin{array}{l}\text { Conflito Inter geracional na } \\
\text { família: Relato de um } \\
\text { projeto terapêutico } \\
\text { singular. }\end{array}$ & Novais MRCG, et al. & 2012 & $\begin{array}{l}\text { Com.Ciências } \\
\text { saúde. }\end{array}$ & BVS & $\begin{array}{c}06- \\
26 / 11 / 2012\end{array}$ & $\begin{array}{l}\text { O trabalho é descritivo, modalidade de relato } \\
\text { de caso. Nas visitas foi aplicado roteiro } \\
\text { semiestruturado contendo o histórico, Os } \\
\text { dados foram compilados nos instrumentos: } \\
\text { genograma, ecomapa, escala de risco e } \\
\text { diagnóstico multiaxial. }\end{array}$ & $\begin{array}{l}\text { O PTS constituiu-se de visita } \\
\text { familiar, formulação de hipóteses } \\
\text { para intervenção, definição de } \\
\text { metas, discussão das metas entre } \\
\text { equipe e família e a reavaliação das } \\
\text { intervenções planejadas. }\end{array}$ & $\begin{array}{l}\text { Projeto Terapêutico } \\
\text { Singular; Genograma; } \\
\text { Ecomapa;Escala de risco; } \\
\text { Conflito intergeracional }\end{array}$ \\
\hline 03 & $\begin{array}{l}\text { A construção de um projeto } \\
\text { terapêutico singular com o } \\
\text { usuário e família: } \\
\text { potencialidades e } \\
\text { limitações. }\end{array}$ & $\begin{array}{l}\text { LGP CARVALHO, et } \\
\text { al. }\end{array}$ & 2012 & $\begin{array}{l}\text { O Mundo da } \\
\text { saúde. }\end{array}$ & BVS & $\begin{array}{c}02 / 04 / 2012 \\
\text { até } \\
10 / 05 / 2012\end{array}$ & $\begin{array}{l}\text { Esse estudo trata-se de um relato de } \\
\text { experiência de acadêmicas do curso de } \\
\text { Enfermagem da Universidade Federal de Mato } \\
\text { Grosso. A partir da análise das informações } \\
\text { coletadas, elencamos os problemas, buscamos } \\
\text { referências bibliográficas, traçamos objetivos e } \\
\text { intervenções. }\end{array}$ & $\begin{array}{l}\text { O Projeto Terapêutico Singular } \\
\text { (PTS), principal instrumento de } \\
\text { trabalho interdisciplinar dos } \\
\text { Centros de Atenção Psicosso- cial } \\
\text { (CAPS), possibilita a participação, } \\
\text { reinserção e construção de } \\
\text { autonomia para o usuário / família } \\
\text { em sofrimento psíquico. O objetivo } \\
\text { foi de descrever as etapas que } \\
\text { constituíram a construção de um } \\
\text { PTS em conjunto com usuária / } \\
\text { família de um CAPS do município de } \\
\text { Cuiabá-MT. }\end{array}$ & $\begin{array}{l}\text { Enfermagem. Saúde } \\
\text { Mental. Assistência em } \\
\text { Saúde Mental. Cuidados } \\
\text { de Enfermagem }\end{array}$ \\
\hline 04 & $\begin{array}{l}\text { Projeto terapêutico } \\
\text {.singular: Ferramenta de } \\
\text { superação do GAP } \\
\text { terapêutico em saúde } \\
\text { mental. }\end{array}$ & $\begin{array}{l}\text { CARVALHO NETO, } \\
\text { FRANCISCO, João, } \\
\text { et al. }\end{array}$ & 2020 & $\begin{array}{l}\text { Enfermagem } \\
\text { em foco. }\end{array}$ & BVS & $\begin{array}{c}28 / 03 / 2020 \\
\text { até } \\
18 / 08 / 2020\end{array}$ & $\begin{array}{l}\text { Estudo descritivo do tipo relato de experiência } \\
\text { sobre a ela- boração de um projeto } \\
\text { terapêutico singular, a partir das experiências } \\
\text { vividas por acadêmicos de Enfermagem da } \\
\text { Universidade Federal do Piaú no segundo } \\
\text { semestre de } 2019 \text { ao acompanhar uma } \\
\text { paciente com transtorno mental. }\end{array}$ & $\begin{array}{l}\text { Relatar a experiência acadêmico- } \\
\text { assistencial de estudantes de } \\
\text { Enfermagem durante a construção } \\
\text { conjunta de um projeto terapêutico } \\
\text { singular com as equipes de atenção } \\
\text { à saúde da família em uma Unidade } \\
\text { Básica de Saúde. }\end{array}$ & $\begin{array}{c}\text { Atenção primária a saúde, } \\
\text { planejamento em saúde, } \\
\text { saúde mental }\end{array}$ \\
\hline
\end{tabular}




\begin{tabular}{|c|c|c|c|c|c|c|c|c|c|}
\hline 05 & $\begin{array}{l}\text { Avaliação do } \\
\text { funcionamento familiar no } \\
\text { contexto da saúde mental. }\end{array}$ & Souza J, et al. & 2011 & Rev Psiq Clín. & BVS & $\begin{array}{l}23 / 12 / 2010 \\
\text { até } \\
13 / 05 / 2011\end{array}$ & $\begin{array}{l}\text { Revisão sistemática da literatura de acordo } \\
\text { com as normas Cochrane nas bases de dados } \\
\text { Medline, PubMed e Psyclnfo, no período de } \\
\text { janeiro de } 1990 \text { a julho de 2009. Foram } \\
\text { considerados artigos nos idiomas inglês, } \\
\text { português e espanhol que apresentassem a } \\
\text { utilização de escalas, questionários e } \\
\text { entrevistas na avaliação da relação familiar no } \\
\text { contexto da saúde mental }\end{array}$ & $\begin{array}{l}\text { O objetivo era verificar quais } \\
\text { instrumentos têm sido utilizados na } \\
\text { avaliação do funcionamento } \\
\text { familiar no âmbito da saúde } \\
\text { mental. A utilização de } \\
\text { instrumentos de avaliação familiar } \\
\text { pode contribuir para o } \\
\text { planejamento de intervenções } \\
\text { terapêuticas e na reabilitação em } \\
\text { saúde mental }\end{array}$ & $\begin{array}{c}\text { Avaliação, relações } \\
\text { familiares, saúde mental, } \\
\text { instrumentos, psiquiatria }\end{array}$ \\
\hline 06 & $\begin{array}{l}\text { O papel da família no } \\
\text { exercício dos direitos do } \\
\text { portador de transtorno } \\
\text { mental: Revisão } \\
\text { bibliográfica. }\end{array}$ & $\begin{array}{l}\text { CONRADO, D. dos } \\
\text { S. ; CANDIDO, M. } \\
\text { C. F. da S. }\end{array}$ & 2014 & $\begin{array}{l}\text { Arq. Ciênc. } \\
\text { Saúde } \\
\text { UNIPAR. }\end{array}$ & BVS & $\begin{array}{l}\text { maio/ago. } \\
2014\end{array}$ & $\begin{array}{l}\text { Esse estudo trata-se de uma pesquisa } \\
\text { bibliográfica do tipo descritiva. O } \\
\text { levantamento bibliográfico foi realizado nas } \\
\text { bases de dados SCIELO, MEDLINE, BVS e } \\
\text { BDENF a partir das seguintes palavras-chave: } \\
\text { família, transtorno mental, e saúde mental. }\end{array}$ & $\begin{array}{l}\text { A família é um grupo formado por } \\
\text { pessoas que compartilham } \\
\text { significados de suas vivências } \\
\text { existenciais. Devido à grande } \\
\text { influência da família na vida de seus } \\
\text { membros, não se pode desvinculá- } \\
\text { la do contexto de saúde mental, } \\
\text { sendo importante conhecer a } \\
\text { dinâmica familiar, bem como a } \\
\text { representação da doença para ela. }\end{array}$ & $\begin{array}{l}\text { Família, transtorno } \\
\text { mental. Saúde mental }\end{array}$ \\
\hline 07 & $\begin{array}{l}\text { Perspectivas atuais sobre a } \\
\text { sobrecarga do cuidador em } \\
\text { saúde mental. }\end{array}$ & $\begin{array}{c}\text { Cardoso I, Vieira } \\
\text { MV, et al. }\end{array}$ & 2012 & $\begin{array}{l}\text { Rev Esc } \\
\text { Enferm USP }\end{array}$ & BVS & $\begin{array}{l}\text { 06/05/2011 } \\
\text { Até } \\
16 / 06 / 2011\end{array}$ & $\begin{array}{l}\text { Foi realizada uma revisão sistemática da } \\
\text { literatura sobre sobrecarga de cuidadores em } \\
\text { saúde mental. Os trabalhos foram se- } \\
\text { lecionados na Biblioteca Virtual de Saúde } \\
\text { (BVS), utilizando-se as palavras-chaves: so- } \\
\text { brecarga do cuidador (caregiver burden). }\end{array}$ & $\begin{array}{c}\text { No dinâmico processo saúde- } \\
\text { doença a condição de } \\
\text { adoecimento, que é uma situação } \\
\text { de crise, acompanha a humanidade } \\
\text { e necessita do cuidado à saúde para } \\
\text { que seja estabelecida a condição de } \\
\text { saúde e equilíbrio do individuo e } \\
\text { coletividade. }\end{array}$ & $\begin{array}{l}\text { Cuidadores, Saúde mental } \\
\text { Enfermagem psiquiátrica, } \\
\text { Estresse Psicológico }\end{array}$ \\
\hline 08 & $\begin{array}{l}\text { Projeto terapêutico singular } \\
\text { na produção do cuidado } \\
\text { integral: Uma construção } \\
\text { coletiva. }\end{array}$ & $\begin{array}{l}\text { DM Pinto, MSB } \\
\text { Jorge, } \underline{\text { AGA Pinto, et }} \\
\text { al. }\end{array}$ & 2011 & $\begin{array}{l}\text { Texto \& } \\
\text { Contexto }\end{array}$ & SCIELO & $\begin{array}{l}2011 \text { Jul- } \\
\text { Set. }\end{array}$ & $\begin{array}{l}\text { Esse estudo trata-se da metodologia de } \\
\text { natureza qualitativa, dentro de uma } \\
\text { perspectiva crítica e reflexiva. O cenário foi o } \\
\text { Centro de Atenção Psicossocial Geral de } \\
\text { Sobral-CE, com } 11 \text { trabalhadores de saúde } \\
\text { mental, cinco familiares e sete usuários. As } \\
\text { técnicas de busca de informações selecionadas } \\
\text { foram as seguintes: entrevista } \\
\text { semiestruturada, grupo focal e observação } \\
\text { sistemática. }\end{array}$ & $\begin{array}{l}\text { A construção de um projeto } \\
\text { terapêutico singular pressupõe a } \\
\text { participação coletiva e uma } \\
\text { concepção de sujeito que } \\
\text { contemple os aspectos } \\
\text { biopsicossocial, espiritual e cultural. } \\
\text { Objetivamos compreender como se } \\
\text { dá a construção do projeto } \\
\text { terapêutico de usuários no Centro } \\
\text { de Atenção Psicossocial de Sobral- } \\
\text { CE. }\end{array}$ & $\begin{array}{l}\text { Saúde Mental, Assistência } \\
\text { integral a saúde, Serviços } \\
\text { de saúde mental }\end{array}$ \\
\hline 09 & $\begin{array}{l}\text { Apoio matricial, projeto } \\
\text { terapêutico singular e } \\
\text { produção do cuidado em }\end{array}$ & $\frac{\text { MSB Jorge, }}{\text { Diniz, LL Lima, et al. }}$ & 2015 & $\begin{array}{l}\text { Texto \& } \\
\text { Contexto }\end{array}$ & SCIELO & $\begin{array}{l}2015 \text { Jan- } \\
\text { Mar. }\end{array}$ & $\begin{array}{l}\text { Esse estudo trata-se de uma investigação } \\
\text { qualitativa, realizada em Fortaleza-CE, no } \\
\text { Centro de Atenção Psicossocial e no Centro de } \\
\text { Saúde da Família. Participaram } 17 \text { sujeitos, }\end{array}$ & $\begin{array}{l}\text { O estudo objetivou compreender } \\
\text { como se conformam o apoio } \\
\text { matricial, projeto terapêutico } \\
\text { singular, e sua interface com a } \\
\text { produção do cuidado em saúde }\end{array}$ & $\begin{array}{l}\text { Saúde Mental, Atenção } \\
\text { primária a saúde, serviços } \\
\text { de saúde mental }\end{array}$ \\
\hline
\end{tabular}


Research, Society and Development, v. 11, n. 1, e47511124505, 2022

(CC BY 4.0) | ISSN 2525-3409 | DOI: http://dx.doi.org/10.33448/rsd-v11i1.24505

\begin{tabular}{|c|c|c|c|c|c|c|c|c|c|}
\hline & saúde mental. & & & & & & $\begin{array}{l}\text { entre profissionais e usuários. Utilizou-se a } \\
\text { entrevista semiestruturada e a observação } \\
\text { sistemática. }\end{array}$ & $\begin{array}{l}\text { mental. O apoio matricial e o } \\
\text { projeto terapêutico singular, } \\
\text { portanto, acontecem no cotidiano } \\
\text { dos serviços, porém com } \\
\text { dificuldades que incidem na } \\
\text { organização e produção do } \\
\text { cuidado. }\end{array}$ & \\
\hline 10 & $\begin{array}{l}\text { Profissionais de saúde } \\
\text { mental e familiares de } \\
\text { pessoas de pessoas com } \\
\text { sofrimento psíquico: } \\
\text { Encontro ou desencontro? }\end{array}$ & TC Constantinidis. & 2017 & Psicologia USP & SCIELO & 2017 & $\begin{array}{l}\text { Nesse estudo foram realizadas entrevistas } \\
\text { semiestruturadas com profissionais de saúde } \\
\text { mental de dois Centros de Atenção } \\
\text { Psicossocial da região Sudeste do país. }\end{array}$ & $\begin{array}{c}\text { Este estudo analisa os impasses } \\
\text { enfrentados pelos profissionais de } \\
\text { saúde mental na inclusão da família } \\
\text { nos projetos terapêuticos de } \\
\text { atenção à pessoa com sofrimento } \\
\text { psíquico. }\end{array}$ & $\begin{array}{l}\text { Saúde Mental, Atenção } \\
\text { Psicossocial , Família, } \\
\text { Centro de atenção } \\
\text { psicossocial }\end{array}$ \\
\hline 11 & $\begin{array}{l}\text { Experiências dos cuidadores } \\
\text { de pessoas com } \\
\text { adoecimento psíquico em } \\
\text { face á reforma psiquiátrica: } \\
\text { produção do cuidado, } \\
\text { autonomia,empoderamento } \\
\text { e resolubilidade. }\end{array}$ & $\begin{array}{l}\text { AAM Firmo, MSB } \\
\text { Jorge }\end{array}$ & 2015 & $\begin{array}{l}\text { Saúde Soc. São } \\
\text { Paulo. }\end{array}$ & SCIELO & 2015 & $\begin{array}{l}\text { Esse estudo trata-se de um estudo de natureza } \\
\text { quali- tativa e de cunho crítico hermenêutico, } \\
\text { realizado em dois Centros de Atenção } \\
\text { Psicossocial (CAPS), cada um em um município } \\
\text { distinto do estado do Ceará, nordeste } \\
\text { brasileiro. }\end{array}$ & $\begin{array}{c}\text { Este estudo objetiva compreender } \\
\text { o lugar da família nos processos de } \\
\text { cuidado e desinstitucionalização, e } \\
\text { a maneira como os arranjos } \\
\text { familiares têm expe rienciado a } \\
\text { proposta reformista e } \\
\text { antimanicomial de oferta dos } \\
\text { serviços substitutivos como política } \\
\text { pública. }\end{array}$ & $\begin{array}{c}\text { Família, cuidado, serviços } \\
\text { comunitários de Saúde } \\
\text { Mental }\end{array}$ \\
\hline 12 & $\begin{array}{l}\text { Sobrecarga e participação } \\
\text { de familiares no cuidado de } \\
\text { usuários de centros de } \\
\text { atenção psicossocial. }\end{array}$ & $\begin{array}{l}\text { TL Reis, CM Dahl, } \\
\text { SM Barbosa, MR } \\
\text { Teixeira, et al. }\end{array}$ & 2016 & Saúde Debate. & SCIELO & $\begin{array}{l}\text { Abril a } \\
\text { junho de } \\
2016\end{array}$ & $\begin{array}{l}\text { Nesse estudo aplicaram-se a Escala de } \\
\text { Sobrecarga dos Familiares de Pacientes } \\
\text { Psiquiátricos e um questionário } \\
\text { sociodemográfico. }\end{array}$ & $\begin{array}{l}\text { Sobrecarga familiar' é o impacto } \\
\text { que o cuidado dedicado a um } \\
\text { paciente pode provocar no } \\
\text { ambiente familiar. O objetivo do } \\
\text { presente estudo foi investigar a } \\
\text { sobrecarga vivida por familiares } \\
\text { cuidadores de usuários atendidos } \\
\text { em Centros de Atenção } \\
\text { Psicossocial. }\end{array}$ & $\begin{array}{l}\text { Cuidadores, serviços de } \\
\text { saúde mental, saúde da } \\
\text { família, transtornos } \\
\text { mentais, psiquiatria } \\
\text { comunitária }\end{array}$ \\
\hline 13 & $\begin{array}{l}\text { Laços entre família e } \\
\text { serviços de saúde mental. }\end{array}$ & $\begin{array}{l}\text { BSR Covelo, } \mathrm{MI} \\
\text { Badaró-Moreira. }\end{array}$ & 2015 & $\begin{array}{l}\text { Interface } \\
\text { Comunicação } \\
\text { Saúde } \\
\text { Educação. }\end{array}$ & SCIELO & 2015 & $\begin{array}{l}\text { Discute-se a participação dos familiares no } \\
\text { cuidado do sofrimento psíquico, por meio de } \\
\text { observação participante e entrevistas. Os } \\
\text { dados foram tratados mediante a análise de } \\
\text { conteúdo. }\end{array}$ & $\begin{array}{l}\text { Foi possível constituir um corpo } \\
\text { analítico de como as dimensões do } \\
\text { cuidado e do sofrimento se } \\
\text { constituem no âmbito familiar. Os } \\
\text { familiares relatam falta de tempo e } \\
\text { espaços em que possam se cuidar, } \\
\text { gerando desconforto frente à } \\
\text { presença do sofrimento psíquico } \\
\text { em suas vidas. }\end{array}$ & $\begin{array}{l}\text { Saúde do trabalhador, } \\
\text { sistema único de saúde, } \\
\text { Apoio matricial }\end{array}$ \\
\hline
\end{tabular}


Research, Society and Development, v. 11, n. 1, e47511124505, 2022

(CC BY 4.0) | ISSN 2525-3409 | DOI: http://dx.doi.org/10.33448/rsd-v11i1.24505

\begin{tabular}{|c|c|c|c|c|c|c|c|c|c|}
\hline 14 & $\begin{array}{c}\text { O projeto terapêutico } \\
\text { singular e as práticas de } \\
\text { saúde mental nos núcleos } \\
\text { de apoio â saúde da família } \\
\text { (NASF) em Guarulhos (SP), } \\
\text { Brasil. }\end{array}$ & $\begin{array}{l}\text { AA Hori, AF } \\
\text { Nascimento. }\end{array}$ & 2014 & $\begin{array}{l}\text { Ciência \& } \\
\text { Saúde Coletiva. }\end{array}$ & SCIELO & 2014 & $\begin{array}{l}\text { A pesquisa, do tipo qualitativa, foi conduzida } \\
\text { no município de Guarulhos (SP), em 2012, } \\
\text { mediante realização de entrevistas semies } \\
\text { truturadas, com profissionais de saúde mental } \\
\text { de núcleos de apoio e observação sistemática. } \\
\text { O método empregado na interpretação foi } \\
\text { análise de conteúdo. }\end{array}$ & $\begin{array}{l}\text { O objetivo deste artigo é analisar a } \\
\text { elaboração de PTS pelas equipes de } \\
\text { saúde mental dos NASF e suas } \\
\text { articulações com serviços da } \\
\text { Atenção Primária à Saúde (APS), da } \\
\text { Atenção Psicossocial e com outros } \\
\text { setores da sociedade. }\end{array}$ & $\begin{array}{l}\text { Atenção primária a saúde, } \\
\text { saúde mental, pesquisa } \\
\text { qualitativa, Avaliação dos } \\
\text { serviços de saúde }\end{array}$ \\
\hline 15 & $\begin{array}{l}\text { Projeto terapêutico em } \\
\text { saúde mental: Práticas e } \\
\text { processos nas dimensões } \\
\text { constituintes da atenção } \\
\text { psicossocial. }\end{array}$ & $\begin{array}{l}\text { MGF } \\
\text { Vasconcelos, } \underline{\mathrm{MSB}} \\
\text { Jorge, et al. }\end{array}$ & 2016 & $\begin{array}{l}\text { Interface } \\
\text { Comunicação } \\
\text { Saúde } \\
\text { educação. }\end{array}$ & SCIELO & Junho/2016 & $\begin{array}{l}\text { Esse estudo trata-se de uma pesquisa } \\
\text { qualitativa, embasada na Hermenêutica. As } \\
\text { narrativas contextualizam um cenário marcado } \\
\text { pelas dimensões epistemológica e técnico- } \\
\text { assistencial da atenção psicossocial. }\end{array}$ & $\begin{array}{l}\text { Objetivou-se compreender o } \\
\text { cuidado psicossocial, tendo como } \\
\text { analisador o projeto terapêutico } \\
\text { dos usuários, a partir das narrativas } \\
\text { de profissionais dos serviços. }\end{array}$ & $\begin{array}{l}\text { Projeto terapêutico, } \\
\text { saúde mental , atenção } \\
\text { psicossocial }\end{array}$ \\
\hline 16 & $\begin{array}{l}\text { Estratégia da atuação } \\
\text { psicossocial e participação } \\
\text { da família no cuidado em } \\
\text { saúde mental. }\end{array}$ & $\begin{array}{l}\frac{\text { M Dimenstein, }}{\text { Sales, E Galvão, et }} \\
\text { al. }\end{array}$ & 2011 & $\begin{array}{l}\text { Revista de } \\
\text { Saúde Coletiva. }\end{array}$ & SCIELO & Abril/2010 & $\begin{array}{l}\text { A pesquisa foi realizada no ambulatório de } \\
\text { saúde mental de Natal entre novembrode } \\
2008 \text { e fevereiro de } 2009 \text {, como parte de um } \\
\text { trabalho de mestrado que objetivava analisar } \\
\text { processos de cronificação em curso nesse } \\
\text { serviço. Foram realizadas } 12 \text { entrevistas, sendo } \\
\text { sete com familiares e cinco com usuários. }\end{array}$ & $\begin{array}{l}\text { Este trabalho tem como objetivo } \\
\text { discutir como familiares de } \\
\text { portadores de transtornos mentais } \\
\text { têm experienciado as mudanças } \\
\text { nas políticas da área, o que pensam } \\
\text { sobre as novas demandas de } \\
\text { participação e como as mesmas } \\
\text { têm impactado na sua relação } \\
\text { cotidiana com os serviços de saúde } \\
\text { mental e nas práticas de cuidado } \\
\text { junto a seus familiares. }\end{array}$ & $\begin{array}{l}\text { Reforma psiquiátrica, } \\
\text { saúde Mental, } \\
\text { reabilitação psicossocial. } \\
\text { Corresponsabilidade, } \\
\text { familia }\end{array}$ \\
\hline 17 & $\begin{array}{l}\text { A família no cuidado em } \\
\text { saúde mental: desafios para } \\
\text { a produção de vidas. }\end{array}$ & $\begin{array}{l}\text { FERREIRA, } \\
\text { Thayane Pereira da } \\
\text { Silva et al. }\end{array}$ & 2019 & $\begin{array}{c}\text { Saúde em } \\
\text { debate. }\end{array}$ & SCIELO & Ago.2019 & $\begin{array}{l}\text { De caráter qualitativo, foi desenvolvido a partir } \\
\text { da produção de narrativas e vivências em um } \\
\text { Centro de Atenção Psicossocial (Caps), tipo III, } \\
\text { de João Pessoa-PB, entre fevereiro e } \\
\text { novembro de 2015. Os pesquisadores } \\
\text { acompanharam a produção de cuidado para } \\
\text { um usuário denominado 'o Capoeirista' }\end{array}$ & $\begin{array}{l}\text { O acontecimento convoca a uma } \\
\text { visualização da família como aquela } \\
\text { que cuida e que também precisa } \\
\text { ser cuidada. Além do que, em } \\
\text { alguns momentos, como na } \\
\text { elaboração do plano de cuidado, } \\
\text { ela pode ser invisível para a equipe } \\
\text { de saúde, sendo apenas solicitada } \\
\text { para se responsabilizar pelo sujeito } \\
\text { em sofrimento psíquico. Talvez o } \\
\text { mais importante não seja delimitar } \\
\text { qual é o lugar que a família deve } \\
\text { assumir na produção do cuidado, } \\
\text { mas quais as diferentes posições } \\
\text { que ela pode assumir no decorrer } \\
\text { dos processos cuidadores. }\end{array}$ & $\begin{array}{l}\text { Saúde mental; Serviços de } \\
\text { saúde mental; Assistência } \\
\text { à saúde mental. }\end{array}$ \\
\hline
\end{tabular}

Fonte: Autores. 
Além do mais, o software Nvivo proporcionou, por parte da pesquisadora, a formação de nós que surgiram a partir da análise dos resultados encontrados nos artigos selecionados o que possibilitou a formação de categorias analíticas, que contribuíram as discussões à frente. Dessa forma, pode-se reconhecer os dois nós que envolvem as principais temáticas descobertas nos artigos que constituem "Família e Projeto terapêutico singular" e "Família e Saúde Mental". A primeira temática abrange os aspectos importantes ao processo da inserção da família no projeto terapêutico singular de pacientes que necessitam da elaboração de um projeto terapêutico, e na segunda temática trata-se também da relevância da família como estratégia de cuidado aos pacientes com transtorno mental. Mostra-nos, ainda, uma visão geral que o problema de "saúde mental e Família" sofreu modificações no decorrer da história e que não se pode pensar no tratamento ao usuário, sem que a família não faça parte desse processo, levando-nos a pensar nas discussões e ações de saúde eficazes quanto ao acompanhamento e desenvolvimento desse paciente na saúde pública.

Dentro do "Nó" "Família e Projeto Terapêutico Singular", percebemos, a partir de uma visão geral, que de todos os estudos expostos, os artigos que mais expressaram situações da Família e Projeto Terapêutico, são: "A construção de um projeto terapêutico singular com usuário e família: potencialidades e limitações" (Carvalho et al., 2012) e o "Projeto Terapêutico Singular na produção do cuidado integral: uma construção coletiva" (Pinto et al., 2011). Colocando-nos uma reflexão sobre o projeto terapêutico singular como um instrumento de trabalho dentro dos centros de atenção psicossocial, possibilitando a reinserção e a constituição da autonomia junto ao usuário/família em sofrimento mental. Portanto, esses dois artigos foram os que mais apresentaram em números de casos sobre a específica temática.

Os seis artigos mostraram uma menor cobertura de referência em relação ao processo da inserção familiar no Projeto Terapêutico Singular, destacamos: a família no cuidado em saúde mental: desafios para a produção de vidas, o conflito intergeracional na família, estratégia da Atenção Psicossocial e a participação da família no cuidado em saúde mental, laços entre família e serviços de Saúde Mental, perspectivas atuais sobre a sobrecarga do cuidador em saúde mental, Projeto Terapêutico Singular - ferramenta de superação do Gap.

Podemos perceber que esses artigos que mostraram a menor cobertura, apresentam referências no que diz respeito à inclusão da família no processo do cuidado a pacientes com transtorno mental, sem mencionar sobre a importância do projeto terapêutico como um cuidado ao usuário.

Então, podemos reafirmar que os autores declaram, em seus escritos, que o projeto terapêutico é baseado conforme as demandas de saúde do usuário, por meio da reciprocidade entre trabalhador/usuário/família, com o objetivo de proporcionar saúde mental. Desse modo, o dia a dia do cuidado em saúde mental abrange as relações entre profissionais de saúde e gestores, usuários, familiares e comunidade (Pinto et al., 2011).

O novo modelo de atenção psicossocial possibilita ao usuário a sua participação no seu próprio tratamento, promovendo a constituição de uma autonomia e reinserção social do paciente através do trabalho, de seus direitos e deveres enquanto cidadão, no lazer e na consolidação dos vínculos familiares e comunitários (Carvalho et al., 2012).

Ainda em associação, temos como segundo Nó, "Família e Saúde Mental", em que podemos compreender que o estudo "A família no cuidado em saúde mental - desafios para a produção de vidas: apresenta o máximo de referências sobre a temática do problema levantado da ligação da família com a saúde mental. Assim sendo, seguidamente com o grau de menos cobertura estão os seguintes artigos: a construção do projeto terapêutico singular com usuário e família, apoio matricial, projeto terapêutico singular e produção do cuidado em saúde mental. O conflito intergeracional na família, laços entre família e serviços de Saúde Mental, o Projeto Terapêutico Singular e as práticas de saúde mental nos Núcleos de Apoio à Saúde da Família (NASF) em Guarulhos e Projeto Terapêutico em Saúde Mental - práticas e processos nas dimensões constituintes da atenção psicossocial. 
Em relação à análise dos estudos, todos os artigos escolhidos na presente revisão estão nesse quadro de representação, mas apenas dois com grau de menos cobertura constam: conflito intergeracional na família (Novaes, 1969) e laços entre família e serviços de Saúde Mental pois estes não evidenciam, em seus estudos, as temáticas em questão (Covelo et al., 2015).

Segundo Ferreira et al (2019), na relação entre o indivíduo e sua família, conforme a Política Nacional de Saúde Mental (PNSM) redirecionou novos procedimentos de cuidado na saúde mental, com o intuito de entender melhor o papel da família no cuidado aos usuários com distúrbio mental, onde o tratamento poderá ser realizado nos centros de atenção psicossocial (CAPS) e na Atenção Primária à saúde através da equipe da saúde da família, entre outros (Ferreira et al., 2019). E pensar nessa família como parte integrada às redes de apoio do paciente, de modo que faça parte das ações propostas por um projeto desse usuário. Portanto as equipes da saúde da família apostam e confirmam o desejo da inclusão da família no processo do cuidado (Ferreira et al., 2019).

A seguir, expomos ainda as 2 categorias de "NÓS" usadas para essa Revisão Integrativa. O primeiro Nó, 1) Família e Projeto terapêutico singular, e depois 2) Família e Saúde Mental. Com total relevância para a fase de análise e discussão dos resultados.

\section{Família e Projeto Terapêutico Singular}

De acordo com o atual grupo, foi elaborada uma nuvem de palavras que nos possibilitou a visualização de algumas palavras, quanto à sua representação, existentes no Nó: Família e Projeto Terapêutico Singular.

Figura 2 - Nuvem de palavras de Família e Projeto Terapêutico Singular.

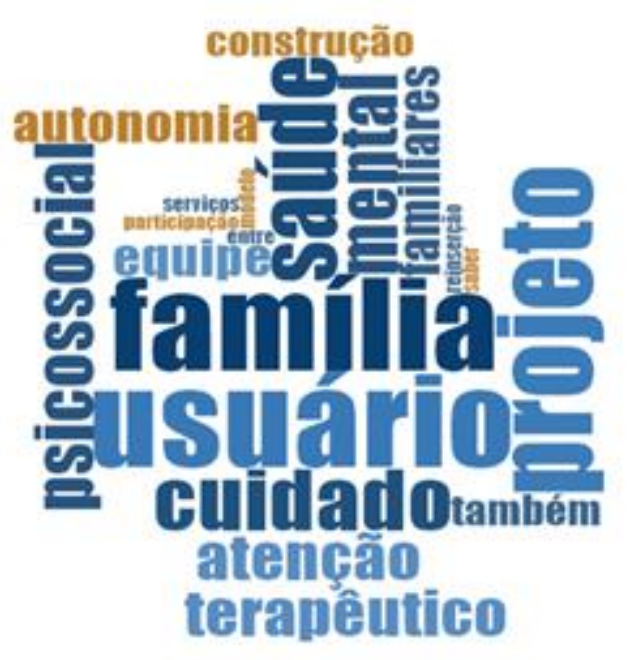

Fonte: software NVivo.

Desse modo, a Figura 2 aparece como resultado da leitura e análise dos 17 artigos, fornecendo categorias de nós a partir dos estudos. Assim sendo, por meio da análise da nuvem de palavras para o primeiro Nó: Família e Projeto Terapêutico Singular, ressalta-se o termo "Família" e "Usuário" como sendo os eixos norteadores de como é baseado o novo modelo de atenção psicossocial que perpassa pela subjetividade dos familiares/usuários na construção do projeto terapêutico, valorizando os cuidados primários em saúde mental (Jorge et al., 2015).

Assim, "Família", "Usuário", "Projeto", estão diretamente interligados refletindo no "Cuidado" e "Atenção" deles como primordiais na construção de um projeto terapêutico, proporcionando a autonomia desse usuário por meio de um cuidado coletivo. Dessa forma, a família é essencial nesse processo terapêutico, assumindo a responsabilidade do cuidado junto ao 
usuário e à equipe da saúde para promover a autonomia do usuário, retomando a sua cidadania e a reinserção social por meio do cuidado de todos (Pinto et al., 2011).

Percebemos, nos estudos, a atenção voltada aos avanços no cuidado em saúde mental por meio do modelo de Atenção Psicossocial através do Projeto Terapêutico Singular, proporcionando ao usuário a sua participação, a sua reinserção social e a busca da construção de sua autonomia (Carvalho et al., 2012). Diante disso, podemos afirmar que as características desse modelo é saber reconhecer as opiniões dos familiares e usuários na construção do projeto terapêutico (Pinto et al., 2011). Portanto, trata-se do trabalho coletivo, em torno do "usuário", incluindo a participação da "Família" e "equipe de saúde", trabalhando, principalmente, as tecnologias relacionais para a construção de um projeto terapêutico no âmbito da atenção "psicossocial", gerando ações de enfrentamentos a essa realidade para o ato de cuidar.

Em consequência disso, o projeto terapêutico singular é criado mediante as necessidades de saúde de cada usuário, seu modo de entender a vida e suas subjetividades, mas devem ser baseados nas tecnologias das relações, como: acolhimento, vínculo e escuta por meio da interação de todos os envolvidos no processo de cuidado, propondo nova maneira de pensar sobre saúde mental nos vários níveis de atenção (Jorge et al., 2015).

Outra questão relevante na elaboração do PTS (Projeto Terapêutico Singular) são que essas tecnologias leves favorecem a participação do usuário/família no tratamento (Pinto et al., 2011). De acordo com Carvalho (2012), o principal mecanismo de trabalho nos Centros de Atenção Psicossocial (CAPS) é o Projeto Terapêutico Singular (PTS) que proporciona a reinserção e a construção de autonomia ao usuário e à família com transtorno mental, onde a partir do crescimento da autonomia do indivíduo estes deverão ser incluídos nas atividades do PTS, por meio de trocas de informações e execuções das ações. Consequentemente, um dos objetivos do CAPS é promover a participação desses familiares no projeto terapêutico, incentivando o usuário a participar do projeto e a sua integração social (Covelo et al., 2015).

Ainda nos estudos de Carvalho (2012), também é fundamental o estímulo aos usuários e aos familiares para relatarem seus sintomas, como medos e ansiedades diante da equipe que esteja presente, onde, através dessas relações, possam ofertar várias possibilidades ao sujeito, à sua autonomia e à sua reinserção social.

A maioria dos estudos apontam um modelo de Atenção Psicossocial, no qual o projeto terapêutico singular é um instrumento utilizado na prática dos serviços dos centros de atenção psicossocial, considerando como uma ferramenta potente no cuidado especial aos usuários atendidos nas unidades, propiciando uma maior autonomia e relações nos momentos vividos dos sujeitos e suas famílias (Hori et al., 2014).

Atualmente, encontra-se nos achados dos artigos selecionados que um dos fatores mais importantes para a construção de um projeto terapêutico singular é a valorização do conhecimento e das opiniões dos usuários/famílias e equipe de saúde, ou seja, do poder terapêutico da palavra e da escuta nesse processo. Ademais, ele é elaborado baseando-se nas necessidades de cada indivíduo, onde o dia a dia do cuidado em saúde mental englobará as relações entre trabalhadores e gestores das unidades, usuários, familiares e comunidade. Esse projeto torna-se singular numa interação horizontal entre trabalhador/usuário/família (Pinto et al., 2011).

Outro aspecto relevante nesse processo de construção do projeto terapêutico tem como base o acolhimento, vínculo, corresponsabilização e autonomia, favorecendo a participação do usuário e família ao tratamento (Pinto et al., 2011). Sendo assim, Pinto (2011) sugere um cuidado na sua plenitude da atenção e na humanização através da ajuda.

Entretanto, para alguns autores, há na produção desse cuidado integral em saúde mental e equipamentos, como as tecnologias leves (acolhimento, vínculo), que contribuem no tratamento do usuário e na permanência dele na unidade. Por isso, com a utilização dessas tecnologias e com a ampliação da clínica, podemos pensar num cuidado em saúde do indivíduo de uma forma integral através do ambiente e nas suas relações. Dessa maneira, importar-se com essa produção do cuidado será um grande avanço para as mudanças nas práticas do campo da saúde mental (Jorge et al., 2015). 
Essa temática tem recebido diversas contribuições teóricas, destacando ainda a produção desse cuidado, em que os profissionais de saúde relatam as dificuldades dos familiares em assumirem o cuidado de seu parente em sofrimento psíquico. Compreendemos que isso se dá em virtude de estar muito presente a cultura do modelo manicomial de tutela e que a responsabilização é algo bastante recente na vida desses familiares. Considera-se que na atenção psicossocial esse pode ser um dos impasses no qual ao procurar manter o usuário na comunidade, produzindo sua autonomia e cidadania viáveis a ele, deve dividir a responsabilidade com familiares e a sociedade. Nesse contexto, a família tem sua parcela de responsabilização pelo seu parente, assim como os profissionais e o estado têm que ter políticas públicas voltadas à atenção em saúde mental, impedindo o usuário ao abandono de si mesmo (Constantinidis, 2017).

Nos estudos Campos E Soares (2005), Pegoraro E Caldana (2006) afirmam o sentido de os familiares concederem a responsabilidade do cuidado à pessoa com transtorno mental ao estado e na realidade as famílias se sentirem abandonadas nas dificuldades em fornecer cuidados, sem apoio e assistência social. Diante disso, a dificuldade de se produzir todos juntos faz com que a responsabilização seja passada mais frente (Constantinidis, 2017).

De todos os estudos encontrados, os que mais refletem sobre episódios da inclusão da família no projeto terapêutico singular de pacientes em sofrimento mental, estão contidos nesses dois artigos: "A construção de um projeto terapêutico singular com usuário e família: potencialidades e limitações" (Carvalho et al., 2012) e o "Projeto Terapêutico Singular na produção do cuidado integral: uma construção coletiva", pois relatam que a construção de um projeto terapêutico baseia-se nas necessidades de cada usuário onde a autonomia do mesmo fará presente nas atividades do PTS quando a família e redes sociais forem envolvidas nesse processo do cuidado, numa relação mútua entre trabalhador/usuário/família através de trocas de informações e efetivação das ações (Pinto \& Jorge et al., 2011).

E ainda referem que, de acordo com o autor Carvalho (2012), após a escolha do usuário ou usuária, a construção de um projeto terapêutico passa por algumas etapas: a primeira etapa trata-se do acolhimento que proporciona uma capacidade de escuta, a criação de vínculo e certeza do acesso na unidade com o comprometimento. Além disso, o acolhimento abrange o compromisso de reconhecer o outro de forma individual, com suas diferenças, alegrias, dores e seu modo de viver a vida. Já com a criação de vínculos serão fortalecidas as relações de compromisso entre equipes, usuário e família resultando numa ligação mais humana e especial.

Entretanto, aparece como a próxima etapa do projeto terapêutico a visita domiciliar, propiciando, por parte da equipe de saúde, uma maior interação com o usuário e família, o que possibilita conhecer a realidade vivenciada por esse sujeito, mostrando a importância do seu envolvimento e inclusão no seu tratamento (Carvalho, 2012).

Evidenciou-se, nos estudos, que os profissionais das equipes de SF das UAPS (Unidade de Atenção Primária à Saúde) e na Atenção Psicossocial (CAPS), devem utilizar-se de estratégias para implementar o desenvolvimento da autonomia e a reinserção social do usuário com apoio de sua família e equipe de trabalhadores da saúde em busca de um mesmo objetivo, construir um projeto terapêutico de acordo com a realidade de cada usuário, contando com o envolvimento de todos (equipe/usuário/família) num cuidado coletivo.

Apresenta-se, então, uma árdua tarefa para que possamos avançar na proposição e nas tentativas de implementação de mudanças nas práticas de saúde e, segundo Constantinidis (2017), uma das dificuldades a serem enfrentadas pela inclusão da família no projeto terapêutico de atenção ao indivíduo com transtorno mental são decorrentes das inseguranças desses profissionais, que, na maioria das vezes, considera as famílias difíceis e opositoras nessa relação.

Dessa forma, em outro estudo, o autor relata que o projeto terapêutico é um serviço

do CAPS e que o profissional dessa rede atua na sua rotina própria de um saber específico, negando a participação do usuário no processo de conflito e articulação junto à equipe responsável e retornando para a clínica tradicional (Vasconcelos et al., 2016). 
E para responder à pergunta deste estudo, sobre qual a importância da inserção da família no projeto terapêutico singular de pacientes em sofrimento psíquico, é necessário que haja uma equipe de saúde capacitada e impulsionada às práticas do diálogo coletivo junto desse usuário e família, incentivando e mostrando a importância da participação deles no projeto e o quão todos ganham com isso, proporcionando ao usuário uma maior autonomia e reinserção social de maneira a tornar-se menos dependente dessa família. E, acima de tudo, que haja uma política pública que facilitem o cuidado em saúde mental.

\section{Família e Saúde Mental}

Para a presente categoria também foi elaborada uma nuvem de palavras, que nos proporcionou a visualização de algumas palavras, quanto à sua representatividade, existentes no Nó: Família e Saúde Mental.

Figura 3 - Nuvem de palavras Família e Saúde Mental.

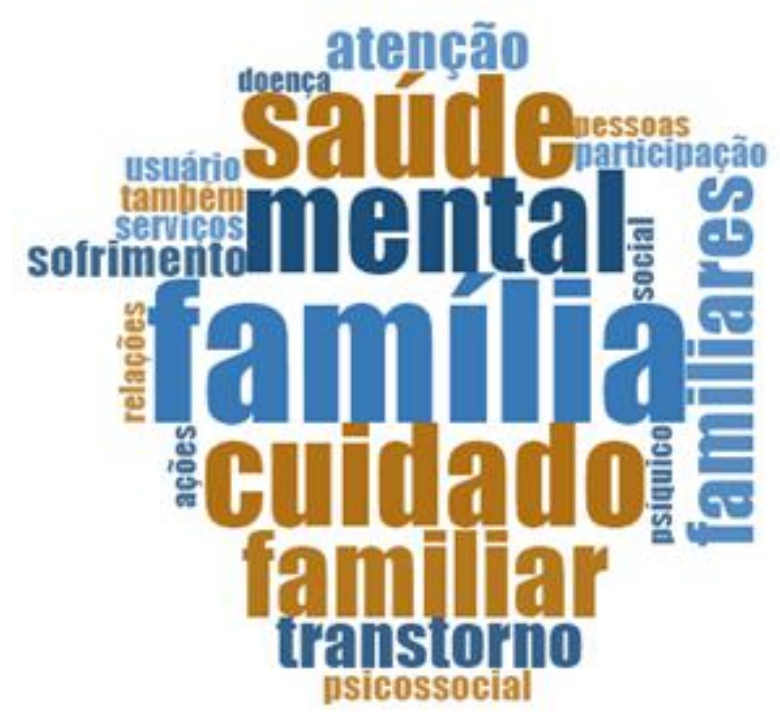

Fonte: software NVivo.

Com a figura acima aparece como resultado da leitura e análise dos 17 artigos e por meio da análise da nuvem de palavras para o segundo Nó: Família e Saúde Mental, ressalta-se o termo "Família" e "Cuidado" como sendo os eixos norteadores, onde após a desinstitucionalização surge o novo modelo de atenção psicossocial, em que a família deve ser incluída na produção do cuidado participando das ações nas redes de apoio ao usuário, sendo reconhecida como um espaço que cuida e necessita ser cuidada (Ferreira et al., 2019).

São relevantes as palavras "Família e "Cuidado", que estão diretamente vinculadas ao "Familiar" e à "Saúde Mental" dos usuários acometidos por algum tipo de "transtorno mental", em que antes da reforma psiquiátrica brasileira o tratamento do paciente era através do isolamento de seus familiares e da sua comunidade, e hoje deve ser baseado nos trabalhos territoriais, como nos centros de atenção psicossocial (CAPS) e na atenção primária à saúde mediante a equipe de estratégia da saúde da família/usuário e a família. Diante disso, as consequências sobre a vida do sujeito é uma melhor qualidade do "cuidado" ao usuário e sua família, criando melhores estratégias para quem cuida e é cuidado (Ferreira et al., 2019).

Ao propormos analisar a função dessa família na produção do cuidado não poderemos deixar de refletir sobre qual o espaço que essa família ocupa numa demanda de um plano de cuidado, entre si e com a equipe de saúde da unidade, também precisamos perceber que essa família, ao vivenciar processos de adoecimento, também necessita de cuidado e para finalizar não esquecermos que essa mesma família faz parte da vida social do usuário (Ferreira et al., 2019). 
Assim, sob os aspectos dos estudos de Conrado (2014), a família influencia muito na vida de seus filiados, por isso essa, por sua vez, não poderá ser excluída no cenário da saúde mental e é relevante conhecer a situação familiar e como é a doença para essa família. Diante disso, após a terceira conferência em saúde mental foi proposta uma nova política dessa saúde, com base na desistitucionalização onde surgiram instituições terapêuticas como substitutas desse sistema asilar, em que impõe aos familiares o papel de cuidador ao indivíduo com transtorno mental. Contudo, nesses serviços deverão apresentar ações de acolhimento à família junto com a Estratégia de saúde da família (Ministério da Saúde, 2002a). Ressaltando que essas atividades terapêuticas são de grande relevância, pois a doença traz mudanças na dinâmica familiar através de estresse em situações de instabilidades e crises.

Entretanto, para que a família tenha uma boa qualidade de vida e atue com o paciente portador de transtorno mental, faz-se necessário o apoio do serviço para dar um suporte tirando as dúvidas e atendendo às suas necessidades (Waidman, Elsen, 2006).

Entre outros, os estudos de Firmo (2015) relatam que nem sempre a família foi vista como essencial no cuidado ao indivíduo com transtorno mental, ao contrário, era vista como fator instigante da doença mental do paciente ou era considerada como uma instituição que deveria ser preservada de um familiar adoecido. Em consequência disso, o convívio com a família poderia afetar os membros mais frágeis da base familiar, por isso observou-se que o ambiente familiar não aparece como o agente causador do transtorno mental (Melman, 2006).

Hoje, segundo Dimenstein (2010), com os projetos científicos e culturais ao redor da insanidade mental as relações entre a família e o paciente de transtorno mental sofreram modificações, no qual um dos grandes desafios consiste na adesão a essas novas convicções, em que a implicação direta na mudança junto aos familiares ou cuidadores desses pacientes está no dever de corresponsabilização pelo cuidado. Portanto, os vínculos com esses familiares passaram a ser fortalecidos, preservados e trabalhados dentro da expectativa do território (Costa-rosa, 2003).

Dessa maneira, os estudos apontam que é indispensável um maior suporte às famílias e/ou aos cuidadores, amparando-os nesse cenário de mudanças, seja na vida familiar, ou pela responsabilização pelo cuidado e na relação com a equipe de saúde da família e nos serviços de Atenção Básica ou Psicossocial (Dimenstein, 2010).

Apresenta-se em outro estudo, que umas das transformações ocorridas no cuidado em saúde mental foi a valorização da família como protagonista na atenção psicossocial, o que se recomenda um apoio aos familiares com intuito de lidarem melhor com suas emoções diante do sofrimento mental, a fim de dar um suporte na execução desse cuidado. Pois, no serviço de Atenção Psicossocial os serviços oferecidos aos familiares são diferentes dos demais, porque a família se disponibiliza a participar efetivamente do projeto terapêutico singular (Covelo, 2015).

Destarte, conclui-se como fundamental a participação da família no cuidado do indivíduo em sofrimento psíquico na atenção psicossocial, porém muitos familiares desconhece a relevância de sua participação no cuidado desse paciente. Consequentemente, fica claro como o envolvimento desses familiares ainda é limitado na rede de saúde mental (Covelo, 2015).

Para que haja um cuidado em saúde livrando o usuário do sofrimento psíquico, supõe-se a disponibilidade de mudança dos processos nas redes dos serviços públicos. Considerando que todas as pessoas da equipe/família/usuário podem ser envolvidas no planejamento, na execução e na avaliação da construção de um projeto terapêutico singular que estão constantemente no processo dinâmico de ensinar-aprender, ou seja, no processo contínuo de trocas, em que o relacionamento interpessoal permita assistir, como bem diz Santos (2000, p. 52).

O cuidado, assim, engloba escuta, respeito ao sofrimento do usuário e sua história, pois o sujeito que busca atendimento pressupõe o encontro de cuidado e acolhimento à sua demanda (Pinheiro, 2009a, Merhy, 2007, 2013a). 
A proposta primordial baseia-se na escuta, uma tecnologia leve-relacional, no modelo de cuidar centrado no usuário: "É o que deveria ocorrer em processos de cuidado em que as histórias de vida do usuário são fundamentais e suas formas de compor os processos de cuidado também", refere Merhy (2013a, p. 256).

Evidenciou-se, neste estudo, que os profissionais das equipes de saúde relatam que alguns familiares apresentam dificuldades em responsabilizar-se pelo cuidado de seu paciente com transtorno mental. Isso se dá, ainda, pela cultura manicomial que se faz ainda presente e chamar os familiares à responsabilização é um tanto recente. Um dos obstáculos da Atenção Psicossocial é dividir a responsabilidade com os familiares e comunidade ao manter o usuário em sociedade, construindo sua autonomia (Constantinidis, 2017).

Em um outro estudo Bandeira et al (2011) declaram que a união dos profissionais de saúde com a família pode ser boa no tratamento do usuário, refletindo na diminuição das internações, conflitos familiares e na sobrecarga desses cuidadores.

Portanto a família deve ser incorporada de uma maneira acolhedora e confortável (Reis et al., 2016).

Dado ao fato de que o empoderamento poderá ser alcançado baseado num aumento de autonomia, junto ao estímulo na criação de projetos por parte da família, da criação de cartilhas a respeito dos direitos dos pacientes com transtorno mental, do fortalecimento das associações e cooperativas de usuários e familiares e outros aspectos (Alves, Oliveira, Vasconcelos, 2013, Reis et al., 2016).

De todos os estudos encontrados, os que mais refletem sobre episódios da inclusão da família no processo do cuidado da saúde mental estão contidos nesses dois artigos: "A família no cuidado em saúde mental: desafios para a produção de vidas" (Ferreira et al., 2019) e "O papel da família no exercício dos direitos do portador de transtorno mental" (Conrado et al., 2014), pois relatam que a visão que eles têm da família é aquela que cuida e que precisa também de cuidados, onde na elaboração do plano de cuidado ela é solicitada a responsabilizar-se pelo individuo em sofrimento psíquico e na construção de um projeto terapêutico baseado nas necessidades de cada usuário .

Assim sendo, em outro estudo, o autor relata que os centros de atenção psicossocial (CAPS) são pontos estratégicos da rede de atenção psicossocial (RAPS), como serviços de saúde de natureza comunitária, compostos por uma equipe multiprofissional que atuam no atendimento a pacientes com transtorno mental (De carvalho neto et al., 2020). A atenção primária à saúde funciona como a porta de entrada no atendimento aos pacientes com transtorno mental, colaborando no processo de cuidado na saúde mental (De carvalho neto et al., 2020).

E para responder à pergunta ao meu segundo Nó deste estudo, sobre qual a relevância da família no cuidado na saúde mental de pacientes em sofrimento psíquico, é necessário que haja uma equipe de saúde capacitada e impulsionada às práticas do diálogo coletivo junto desse usuário e família, incentivando e mostrando a importância da participação deles no processo de cuidado da saúde mental, proporcionando ao usuário uma maior autonomia e reinserção social de maneira a tornar-se menos dependente dessa família.

\section{Considerações Finais}

A presente revisão da literatura buscou responder a questões referentes à inserção da família no projeto terapêutico singular de pacientes em sofrimento psíquico, identificando os desafios dessa família perante o novo modelo de atenção psicossocial e os avanços no processo de cuidado em saúde mental, contando com a participação da família/usuário/equipe configurando em um serviço em que todos estão envolvidos coletivamente. Além disso, tentou-se mostrar a relevância da participação dessa família e usuário junto à equipe de profissionais na construção de um projeto terapêutico singular.

Buscou-se analisar a transformação da realidade de um usuário através da participação dele e de sua família na elaboração de um projeto terapêutico, onde, anteriormente, essa pessoa não tinha consciência sobre seu estado de saúde e, após essa vivência, esse indivíduo tem maiores informações de si mesmo e sobre seu tratamento, podendo atuar de uma forma 
crítica. Em consequência disso, a realização deste projeto possibilita maiores esclarecimentos sobre a doença mental, sobre os serviços oferecidos, permitindo uma avaliação crítica ao tratamento por parte do usuário e da família, além de proporcionar a autonomia e a reinserção social desse sujeito na sua comunidade.

Os estudos ainda trazem o "olhar" sobre algumas dificuldades encontradas na construção do projeto terapêutico singular, como a alteração entre teoria e prática diante do novo modelo e os instrumentos usados, como a falta da utilidade do PTS no dia a dia dos serviços prestados a essas pessoas. Nesse contexto, cabe salientar que vivemos um processo de mudanças nas práticas dos serviços e que para entendermos que mudar requer criar práticas e uma desconstrução do modelo antigo (manicomial), portanto caracteriza-se como um desafio perante o cumprimento da reforma psiquiátrica.

Torna-se necessário destacar outros avanços nesse processo, como a participação e a flexibilização do usuário e da família que poderão ser transformadas de acordo com as necessidades de cada um. Por isso, podemos compreender o projeto terapêutico na busca em abranger os problemas de saúde mais complexos que surgem nos serviços, contando com a participação de uma equipe multidisciplinar, proporcionando troca de saberes, práticas e conhecimentos na inclusão do usuário no seu meio específico.

Em face deste estudo, mostra-se que ao pensarmos no cuidado em saúde mental significa pensar no sujeito na sua total plenitude, no ambiente onde está inserido e nas suas relações, pois o cuidado é construído levando-se em conta diversos contextos: sociais, econômicos, familiares psicológicos e culturais. Por conta disso, envolver-se com o cuidado em saúde torna-se um desafio para além dos relatos se aproximando das práticas do novo modelo assistencial.

\section{Referências}

Boff, L. (1999). Saber Cuidar: ética do ser humano - compaixão pela Terra. Vozes.

Botelho, L. L. R., Cunha, C. C. A., \& Macedo, M. (2011). O método da revisão integrativa nos estudos organizacionais. Gestão e Sociedade, 5(11), 121-36.

Cardoso, L. et al. (2012). Perspectivas atuais sobre a sobrecarga do cuidador em saúde mental. Revista da Escola de Enfermagem da USP, 46(2), 513-7.

Carvalho, L. G. P. et al. (2012) A construção de um Projeto Terapêutico Singular com usuário e família: potencialidades e limitações. O mundo da saúde, $36(3), 521-525$

Carvalho neto, F. J. et al. (2020). Projeto Terapêutico Singular: ferramenta de superação do GAP terapêutico em saúde mental. Enfermagem em Foco, Brasília, 11(4), 1-9.

Conrado, D. S., \& Candido, M. C. F. S. (2014). O papel da família no exercício dos direitos do portador de transtorno mental: revisão bibliográfica. Arq. ciências saúde UNIPAR, Umuaruma, 18(2), 121-126.

Constantinidis, T. C. (2017). Profissionais de saúde mental e familiares de pessoas com sofrimento psíquico: encontro ou desencontro? Psicol. USP, 28(1), 2332 .

Covelo, B. S. R., \& Badaró-moreira, M. I. (2015). Laços entre família e serviços de Saúde Mental: a participação dos familiares no cuidado do sofrimento psíquico. Interface-Comunicação, Saúde, Educação, 19(1), 1133-1144.

Dimenstein, M. et al. (2010). Estratégia da Atenção Psicossocial e participação da família no cuidado em saúde mental. Physis: Revista de Saúde Coletiva, 20(1), 1209-1226.

Ferreira, T. P. S. et al. (2019). A família no cuidado em saúde mental: desafios para a produção de vidas. Saúde em Debate, 43(121), 441-449.

Firmo, A. A. M., \& Jorge, M. S. B. (2015). Experiências dos cuidadores de pessoas com adoecimento psíquico em face à reforma psiquiátrica: produção do cuidado, autonomia, empoderamento e resolubilidade. Saúde e sociedade, 24(1), 217-231.

Furtado, J. P., \& Onocko-campos, R. (2005). A transposição das políticas de saúde mental no Brasil para a prática nos novos serviços. Rev. Latinoam. Psicopat. Fund., 8(1), 109-122.

Franco, T. B., \& Magalhães júnior, E. M. (2006). Integralidade na Assistência à Saúde: organização das linhas de cuidado. In: MERHY, E.E. (Org.) $O$ Trabalho em Saúde: olhando e experienciando o SUS no cotidiano. São Paulo: Hucitec, cap. 8, 125-134

Hori, A. A., \& Nascimento, A. F. (2014). O Projeto Terapêutico Singular e as práticas de saúde mental nos Núcleos de Apoio à Saúde da Família (NASF) em Guarulhos (SP), Brasil. Ciência \& Saúde Coletiva, 19(8), 3561-3571.

Jorge, M. S. B. et al. (2015). Apoio matricial, projeto terapêutico singular e produção do cuidado em saúde mental. Texto \& Contexto-Enfermagem, 24(1), 112-120, mar. 2015. 
Research, Society and Development, v. 11, n. 1, e47511124505, 2022

(CC BY 4.0) | ISSN 2525-3409 | DOI: http://dx.doi.org/10.33448/rsd-v11i1.24505

Lage, M. C. (2012). Utilização do software NVivo em pesquisa qualitativa: uma experiência em EaD. ETD - Educ. Tem. Dig., 12(1), 198-226.

Merhy, E. E. (1999). O ato de governar as tensões constitutivas do agir em saúde como desafio permanente de algumas estratégias gerenciais. Ciência \& Saúde Coletiva, 4(2), 305-315.

Merhy, E. E., \& Franco, T. B. (2003). Por uma composição técnica do trabalho centrada no campo relacional e nas tecnologias leves. Saúde em Debate, $27(65), 1-13$.

Merhy, E. E, \& Onocko, R. (Orgs.). (1997). Agir em saúde: um desafio para o público. HUCITEC.

Novaes, M. R. C. G. et al. (2012). Conflito intergeracional na família. Com. Ciências Saúde, 24(2), 169-178.

Pinto, D. M. et al. (2011). Projeto terapêutico singular na produção do cuidado integral: uma construção coletiva. Texto Contexto - Enfermagem, 20(3), 493502.

Reis, T. L. et al. (2016). Sobrecarga e participação de familiares no cuidado de usuários de Centros de Atenção Psicossocial. Saúde em Debate, 40(1, 70-85.

Souza, J. et al. (2011). Avaliação do funcionamento familiar no contexto da saúde mental. Archives of Clinical Psychiatry, 38(1), $254-259$.

Tenório, F. (2002). A reforma psiquiátrica brasileira, da década de 1980 aos dias atuais: história e conceitos. História, Ciência, Saúde, 9(1), 25-59.

Vasconcelos, M. G. F., \& Jorge, M. S. B. (2013). Projeto terapêutico como dispositivo de cuidado em saúde mental. Fortaleza: EdUECE.

Vasconcelos, M. G. F. et al. (2016). Projeto Terapêutico em Saúde Mental: práticas e processos nas dimensões constituintes da atenção psicossocial. InterfaceComunicação, Saúde, Educação, 20(1), 313-323. 